\title{
$\mathrm{POD}$ 에 의한 하이브리드 로켓 연소실의 유동특성 해석
}

박차렴, 이창진*

\section{Proper Orthogonal Decomposition Analysis of Flow Characteristics in Hybrid Rocket Engine}

Charyeom Park and Changjin Lee*

Department of Aerospace Engineering, Konkuk University

\begin{abstract}
POD analysis has been done to investigate the internal flow characteristics using LES calculation results of hybrid rocket combustion chamber. The special emphasis was put on the change in the mode energy distribution caused by the installation of diaphragm compared to the baseline case. Also the comparison was made to investigate the effect of wall blowing on the changes in the mode energy between the regions near and far from the diaphragm. For baseline case, POD results clearly distinguish the primary mode containing most of flow energy from the rest of flow modes (2-9 mode) depicting small scale modes. Also, the increase in the energy of flow modes 2-5 is responsible for the formation of relatively large scale structures due to diaphragm. In addition, the comparison of mode energy distributions of flow fields with diaphragm shows similar patterns in both wall blowing and no blowing case. This implies that the local increase in regression rate just after the diaphragm is directly associated with the increase in energy distributions of 2-5 modes.
\end{abstract}

\section{초 록}

하이브리드 로켓 연소실 내부 유동장에 대한 수치계산 결과에 POD기법을 적용하였다. 특히, 다이어프램 설치에 따른 유동모드 변화를 분석하여, 연소특성에 미치는 영향을 해석 하였다. 또한, 다이어프램이 있는 연소실에서 표면 분출유동의 유무에 따른 POD를 적용하 여 분출유동이 연소실 내부 유동특성에 미치는 영향을 판단하였다. 10 개의 모드를 사용하 여 기본형상에 대한 $\mathrm{POD}$ 결과를 살펴보면 주 유동을 나타내는 모드 1 과 벽면 근처의 작 은 크기 유동인 2-9 모드 사이의 구분이 분명하게 나타났다. 다이어프램을 설치한 형상의 $\mathrm{POD}$ 결과, 모드 2 부터 5 의 에너지가 증가하였는데 이것은 다이어프램 주변 순환영역에서 생성되는 유동 때문인 것으로 보인다. 한편, 다이어프램 주위 영역의 유동특성을 보여주는 모드 2-5와 후류 벽면의 유동특성을 보여주는 모드 6-9의 에너지 분포가 분출유동 유무에 관계없이 비슷한 특성을 나타냈다. 따라서 연소율이 다이어프램 근처에만 국부적으로 증 가하는 이유는 다이어프램 후류에 형성되는 비교적 큰 크기의 유동모드 2-5의 에너지가 증가되었기 때문인 것으로 분석된다.

Key Words : Proper Orthogonal Decomposition(POD), Hybrid Rocket Engine(HRE), Turbulent Energy(난류에너지), Large Eddy Simulation(LES)

† Received: January 20, 2014 Accepted: March 31, 2014

* Corresponding author, E-mail : cjlee@konkuk.ac.kr http:/ /journal.ksas.or.kr/ pISSN 1225-1348 / eISSN 2287-6871 


\section{I. 서 론}

하이브리드 로켓은 일반적으로 고체연료와 액 체산화제가 반응하여 추력을 발생시킨다. 고체연 료는 고온의 연소가스로부터 열전달로 인해 기화 되고, 확산 및 대류를 통해 산화제와 혼합되어 연소된다. 하이브리드 로켓의 연소실 내부유동은 다양한 특성을 지닌 난류구조와 이에 따른 복잡 한 열전달 특성을 보여준다. 즉, 연료의 벽면 근 처에 생성되는 경계층 내부의 확산화염으로부터 연료 표면으로 열전달이 일어나기 때문에, 유동 특성 변화는 경계층 내부의 열전달 특성과 밀접 한 관계가 있다. 연소실 내부의 유동특성 분석을 통해 산화제와 연료 사이의 연소특성이나 연소율 변화를 예측할 수 있다. 따라서 하이브리드 로켓 의 연소과정을 통합적으로 이해하기 위해서는 연 소실 내부 유동특성에 대한 연구가 필요하다[1].

하이브리드 로켓 연소실 벽면 근처에 존재하 는 난류구조는 다양한 크기를 지니고 있다. 연소 실 벽면 근처에는 고체연료가 기화되어 유동 진 행방향의 수직으로 분출유동을 발생시키는데, 이 때 축방향의 유동장과 만나 상호간섭으로 인한 와류를 형성하기 때문에 유동특성이 복잡해지고, 다양한 크기를 지닌 난류구조가 발생한다. 이러 한 다양한 구조들이 한정된 공간에 섞여있으면, 난류 구조의 변화를 관찰하는 것이 어려워진다. 특히, 벽면 주위에서 발생하는 작은 크기의 난류 구조가 큰 구조에 섞여있으면 직접적으로 관찰하 기가 매우 어렵다. 그럼에도 불구하고, 작은 크기 의 난류구조를 분석하는 것은 벽면 근처에서 발 생하는 유동 메커니즘이 하이브리드 로켓의 연소 율에 중대한 영향을 미치고 있기 때문이다.

작은 크기의 난류구조 변화를 분석하는 방법 으로 POD(Proper Orthogonal Decomposition) 기법이 있다. $\mathrm{POD}$ 분석은 여러 특성이 포함된 고차원의 분석 대상을 직교좌표로 구성된 여러 개의 저차원 대상(모드)으로 변환하는 기법이다 [2]. 이를 하이브리드 로켓에 적용하면 연소실 내 부 유동을 구성하고 있는 다양한 난류구조를 에 너지 크기에 따른 모드 별로 관찰할 수 있다. 따 라서 상대적으로 크기가 큰 난류구조를 독립적으 로 관찰하는 동시에, 벽면 근처에 분포되어 있는 작은 크기의 난류구조의 형태 및 거동을 분리하 여 관찰할 수 있다[3]. 예를 들면, 실린더 주위를 지나는 유동에 대한 $\mathrm{POD}$ 분석을 통해 전체 유 동장으로부터 Karman 와류를 포함하고 있는 모 드를 관찰할 수 있다[4]. 아울러 연소실 내부 빛 방출을 스냅사진으로 포착하여, 발생되는 모드를
내부 음향 진동과 연관지어 분석하거나, 화염안 정기에서 반응에 의한 화염 스냅사진에 대한 $\mathrm{POD}$ 를 통해, 순환영역을 중심으로 연소안정성이 증가하는 것을 확인하는 등 유동장에 대한 다양 한 연구에 $\mathrm{POD}$ 가 활용되었다 $[5,6]$.

한편, 추진제 연소율은 하이브리드 로켓의 성 능과 직접적인 관련이 있기 때문에 연소율을 높 이기 위한 다양한 방법이 시도되고 있다[7-9]. 다 이어프램을 연소실 입구 또는 중간에 설치하는 방법은 다이어프램 주변에 강한 난류를 발생시키 며, 열전달을 증가시켜 연소율을 향상시킨다. 그 러나 연소율은 다이어프램 주변에만 국부적으로 증가하므로, 전반적으로 불균일한 연소율 변화가 발생한다는 단점이 존재한다.

본 논문에서는 하이브리드 로켓 연소실의 내 부 유동장에 대한 수치계산 결과에 $\mathrm{POD}$ 기법을 적용하였다. 특히, 다이어프램을 설치한 경우 작 은 크기의 난류구조가 관찰되는 유동모드가 어떤 변화를 하는지 분석하여, 이러한 인자들이 연소 특성에 미치는 영향을 난류관점에서 해석하였다. 또한, 다이어프램이 설치된 형상에서 고체연료의 분출유동 모사 여부에 따른 수치계산 결과에 대 해서도 POD기법을 적용하여, 분출유동이 연소실 내부 유동특성에 미치는 영향도 분석하였다.

\section{II. 본 론}

\section{1 연소실 내부유동에 대한 POD 해석}

\subsection{1 $\mathrm{POD}$ 분석}

본 논문에서는 에너지의 성분을 잘 표현하는 속도 계산결과를 사용하여 $\mathrm{POD}$ 를 수행하였다 [10]. $\mathrm{POD}$ 를 수행하는 과정에는 수치계산 결과 를 사용하여 각 모드를 찾는 절차가 포함되는데, 이 때 많은 시간이 소요된다. 따라서 3D 형상에 대한 계산결과를 유동 진행방향으로 잘라내어 $2 \mathrm{D}$ 결과로 변환 후 $\mathrm{POD}$ 분석하였으며, 계산 양 과 시간을 줄였다.

한편, 속도장인 $U(x, y, t)$ 를

$$
U(x, y, t)=U_{x, y}^{t}=\left[\begin{array}{cccc}
u_{11}^{1} & u_{11}^{2} & \ldots & u_{11}^{N} \\
u_{21}^{1} & u_{21}^{1} & \ldots & u_{21}^{N} \\
\vdots & \vdots & \ddots & \vdots \\
u_{l m}^{1} & u_{l m}^{2} & \ldots & u_{l m}^{N}
\end{array}\right]
$$

과 같이 구성하여, 일정한 시간 간격에 따른 스 냅사진 계산결과를 시간 및 공간에 대한 행렬로 구성하였다[11]. 이 때, $l, m$ 및 $N$ 은 각각 $x, y$ 방 
향의 격자순서와 스냅사진의 순번을 의미한다. 정렬된 속도장에서 각각의 스냅사진 간 2점상관 관계식 $C=U^{T} U$ 를 통해 정사각행렬 $C$ 를 생 성한 후, 각 스냅사진 $i$ 에 대한 고유치 계산인 $C A^{i}=\lambda^{i} A^{i}$ 를 통해 고유값 $\lambda^{i}$ 및 고유벡터 $A^{i}$ 를 구한다. 이 때, 모든 고유값은 에너지 개넘에 서 0 이상의 실수여야 하며,

$$
\lambda_{1}>\lambda_{2}>\lambda_{3}>\cdots>\lambda_{N}=0
$$

과 같이 고유값이 큰 것부터 순서대로 각 모드를 할당받는다. 최종적으로 구하고자 하는 각 모드 값 $\varphi^{i}$ 는

$$
\varphi^{i}=\frac{\sum_{n=1}^{N} A_{n}^{i} u^{n}}{\left\|\sum_{n=1}^{N} A_{n}^{i} u^{n}\right\|}
$$

의 식을 이용하여 구한다.

속도 계산결과는 $\mathrm{POD}$ 분석을 통해 스냅사진 개수만큼의 모드로 나뉘며, 다음의 식으로 나타 낼 수 있다.

$$
U(x, y, t)=\sum_{k=1}^{N} a_{i}(t) \varphi^{i}(x, y)
$$

여기서 $a_{i}(t)$ 는 시간에 대한 임의의 계수를 의미 하며, 이 계수를 구하기 위해 $a_{i}(t)=\varphi^{i}(x, y) u^{n}$ 식을 사용한다. 더 구체적인 POD 분석방법에 대 한 설명은 참고문헌[12]에 상세히 소개되어 있다.

\section{2 연소실 내부 유동장 계산}

\subsubsection{LES 수치계산}

$\mathrm{POD}$ 분석을 위한 연소실 내부유동장을 얻기 위하여 화학반응을 포함하지 않은 비반응 유동에 대한 수치계산을 수행하였다[13]. 또한 난류유동 에 대한 해석을 위하여 LES기법을 사용하였다. $\mathrm{LES}$ 는 특정 크기 이상의 유동특성에 영향을 미 치는 와류를 관찰할 수 있도록 하여, 하이브리드 연소실 내부 유동의 작은 크기의 난류구조를 볼 수 있도록 하기 때문에 유용하다. 원통모양의 연 소실 내부를 다이어프램 없이 계산한 것을 기본 형상으로 선정했으며, 다이어프램을 설치한 형상, 다이어프램을 설치하였으나 고체연료 표면에서의 분출유동을 모사하지 않은 것에 대해 추가적으로 계산하였다. 이 때, 분출유동은 연소실 벽면에 수 직방향으로 속도가 발생하도록 모사하였으며, 그 크기는 다이어프램이 설치된 지점 $(x / D=0)$ 부터
연소실 끝단 $(x / D=15)$ 에 이르기까지 주 유동속도 의 $0 \%$ 에서 $3 \%$ 로 증가하도록 선형적으로 모사하 였다. 수치계산에서 레이놀즈수는 15,300이며, 삽 입된 격자수는 기본형상의 경우 약 210 만개, 다 이어프램을 설치한 형상의 경우 약 290 만개이다. 계산 능력과 정확도 검증에 대한 결과는 참고문 헌[13]에 잘 설명되어 있다.

\section{3 계산 결과 및 분석}

\subsubsection{LES 수치계산 결과 및 복원}

수치계산을 통해 연소실 내부 유동장을 구하 였다. $\mathrm{POD}$ 분석은 유동 계산결과 중 시간 흐름 에 따른 10 개 스냅사진을 사용하였다. 더 많은 스냅사진을 사용한다면 더 많은 모드를 획득할 수 있으며, 각각의 난류구조가 가지는 순환주기 를 많이 포함할 수 있다. 따라서 모드의 시간 변 화에 따른 거동을 보다 정밀하게 관찰할 수 있 다. 그러나 본 논문의 목적은 난류구조의 위치, 크기, 형태 등을 관찰하여 유동특성 변화를 분석 하고 주 유동에 의한 큰 에너지 크기의 유동과 벽면 및 다이어프램에 의한 작은 에너지의 유동 변화를 관찰하는 것이기 때문에, 연소실 내부 속 도분포를 대표하는 10 개의 스납사진만을 통해서 도 작은 크기의 구조가 연소실 내부에 미치는 영 향을 난류관점에서 충분히 분석해낼 수 있다. 또 한 모드를 너무 세분화시키면 미미한 에너지 차 이를 갖는 모드로 나뉘기 때문에, 계산량 증가에 비해 얻는 효과가 매우 미미하다. 따라서 경험적 으로 적당한 개수의 스냅사진을 사용하여 최적의 $\mathrm{POD}$ 결과를 얻을 수 있어야 한다. 본 연구에서 는 10 개의 스냅사진을 활용한 POD 분석을 통하 여 연소실 내부의 유동특성 분석을 시도하였다.

한편, 연소실 내부 속도장에 대한 POD 분석이 적절하게 이루어졌는지 검증하기 위하여 유동장 계산결과와 분리된 $\mathrm{POD}$ 모드의 재조합 결과를 비교하였다. Fig. 1은 기본형상 및 다이어프램을 설치한 유동장 계산 결과와 분리된 $\mathrm{POD}$ 모드의 재조합 결과를 비교한 그림이다. 모드 1 부터 모 드 9 까지 사용하여 복원하였으며, 모드 10 은 에 너지 분포가 $0 \%$ 이므로 복원과정에 제외되었다. 이는 식 (2)와 같이, $\mathrm{POD}$ 를 수행하기 위해 고유 치 문제를 푸는 과정에서 통상적으로 마지막 고 유치를 0 으로 지정해주기 때문이다[12]. 재조합을 통한 복원율은 평균 제곱근 편차 방식으로,

$$
\sqrt{\frac{\sum_{k=1}^{m \times l}\left(u_{r e, k}-u_{\text {mean }, k}\right)^{2}}{m \times l}}
$$




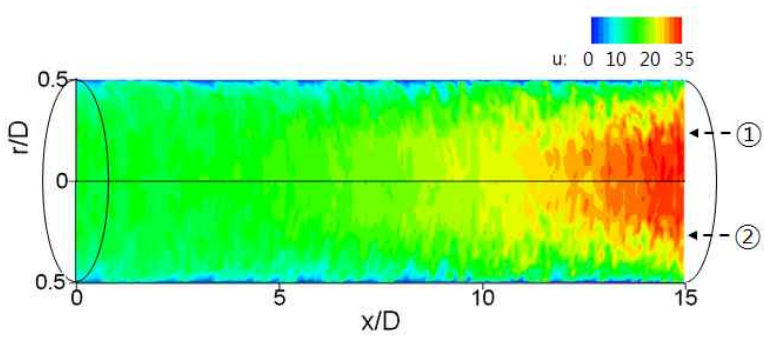

(a) Baseline

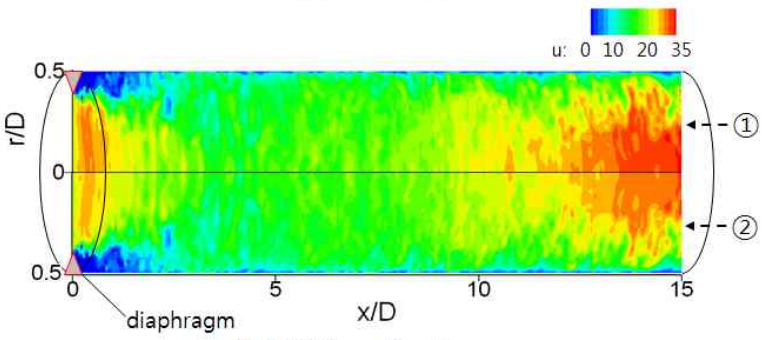

(b) With a diaphragm

Fig. 1. Comparison between CFD results (1) and reconstructed data (2)

식을 사용하였다. 연소실 기본형상과 다이어프램 을 설치한 경우, 각각 $0.0136,0.0134$ 의 매우 작은 평균 제곱근 편차를 나타내고 있다.

\subsection{2 기본형상에 대한 $\mathrm{POD}$ 분석}

다이어프램을 설치하지 않은 연소실 기본형상 의 유동장을 $\mathrm{POD}$ 로 분석하였다. 기본 형상의 경 우, 크게 모드 1과 나머지 모드로 나누어 분석할 수 있다. 모드 1 은 축 방향으로 진행하는 주 유

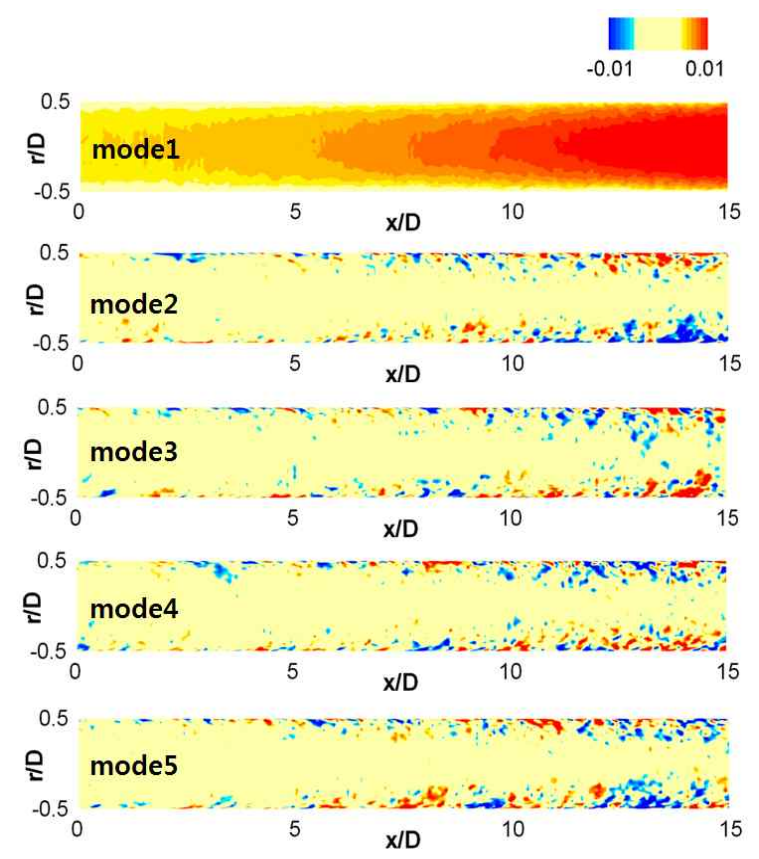

Fig. 2. POD results without diaphragm; mode 1 to 5
동의 에너지를 나타내고 있으며, 모드 2부터 모 드 9 까지는 벽면 주변을 지나면서 생성되는 작은 크기의 난류구조를 의미한다. Fig. 2을 살펴보면, 모드 2 부터 5 까지 발생되는 난류구조가 비슷한 크기를 지닌다. 이를 통해 다이어프램을 설치하 지 않은 경우 난류구조가 복잡하지 않으며, 각 모드가 비슷한 에너지 크기를 가진다는 것을 확 인할 수 있다. 한편, 연소실 후류로 갈수록 벽면 의 분출유동과 축 방향 유동과의 간섭으로 인한 난류구조가 증가하는 것을 확인할 수 있다.

\subsection{3 다이어프램을 설치한 유동장의 POD 분석}

다이어프램이 설치된 유동장에 $\mathrm{POD}$ 를 수행하 여 기본형상과의 유동특성 차이를 분석하였다. Fig. 3은 다이어프램을 설치한 유동장의 $\mathrm{POD}$ 결 과 중 모드 2 부터 모드 5 까지 유동 분포를 나타 내고 있다. 기본형상에 대한 $\mathrm{POD}$ 결과와 마찬가 지로, 모드 1은 축 방향의 주 유동 에너지를 보 여준다. 그러나 모드 2 부터 모드 5 까지는 기본형 상의 $\mathrm{POD}$ 결과와는 달리 다이어프램에 가까운 영역을 중심으로 난류구조가 발생되고 있다. 이 는 다이어프램을 지나면서 급격한 속도 변화를 거치며 다양한 크기의 와류 및 순환영역이 형성 되기 때문이다. 한편, 모드 2에서 모드 5 까지 나 타나는 난류구조는 그 크기와 분포가 축 방향으 로 변화되고 있다. 즉, 모드 수가 늘어남에 따라 난류구조의 크기는 점차 작아지며, 후류로 갈수 록 난류구조의 분포영역이 넓어진다. 이는 기본
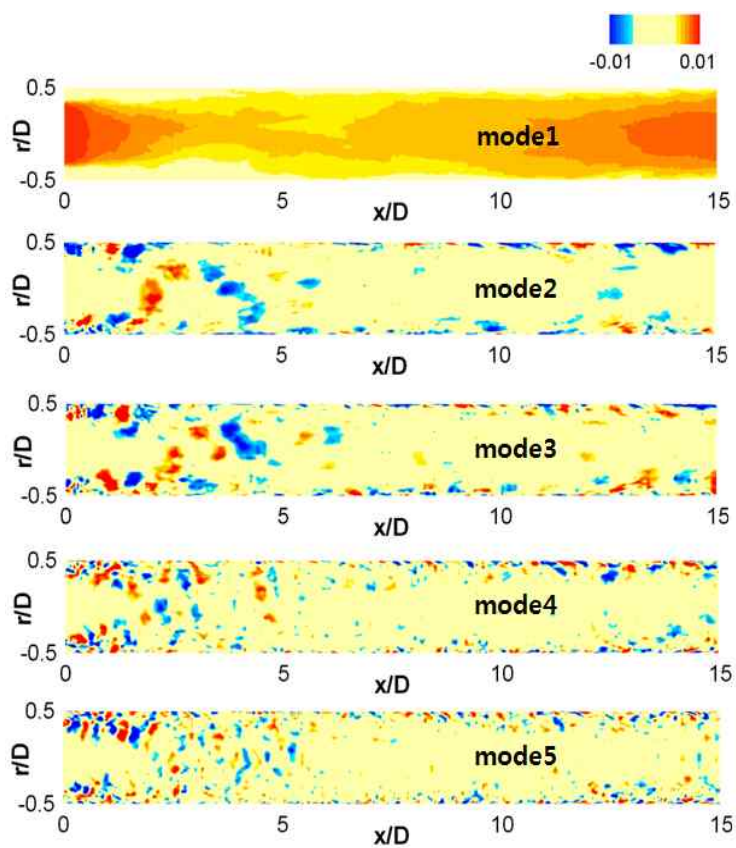

Fig. 3. POD results with diaphragm; mode 1 to 5 
형상의 모드 2 부터 모드 9 까지 모두 비슷한 크기 의 유동 에너지를 지녔던 것과는 다르게, 다이어 프램을 지나면서 발생하는 와류 등으로 인해 다 양한 크기를 지닌 난류구조가 생성되었기 때문인 것으로 보인다.

또한, $\mathrm{POD}$ 결과로 나타나는 각 모드 사이에는 에너지의 전달 또는 교환이 일어나는 것으로 알 려져 있는데[14], 에너지 캐스케이드 (energy cascade) 이론에 의해 난류구조의 크기가 점차 작아지는 방향으로 에너지 전달이 발생한다.

Figure 4는 다이어프램 설치 유무에 따른 유동 장의 $\mathrm{POD}$ 결과를 모드별 에너지 크기에 따라 정리한 것이다. 모드 1 이 차지하는 에너지 비중 은 다이어프램 설치 여부와 관계없이 약 $97 \%$ 이 상으로, 유동장 전체 에너지의 대부분을 차지한 다. 한편, 다이어프램 주변의 유동특성을 보여주 는 모드 2에서 모드 5까지의 에너지 비중은 다이 어프램을 설치한 경우가 기본형상의 경우보다 크

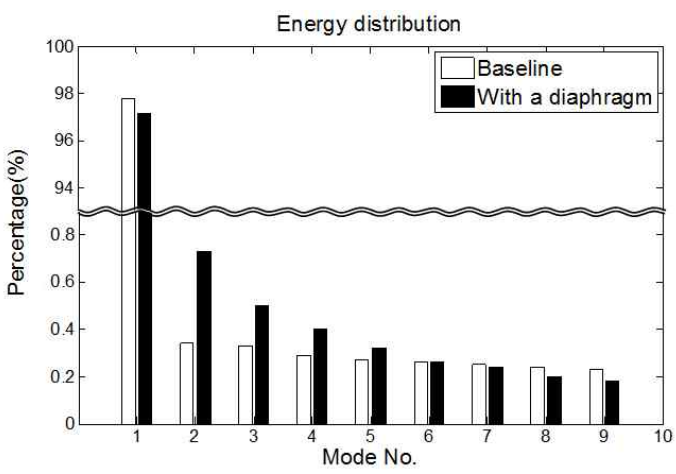

Fig. 4. Comparison of energy distribution between with and without diaphragm
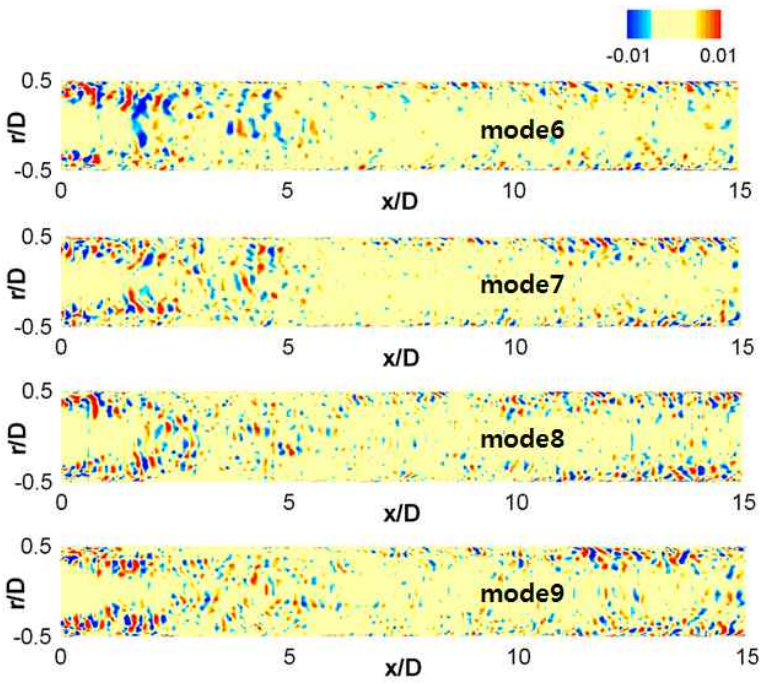

Fig. 5. POD results with diaphragm; mode 6 to 9
게 나타난다. 이는 다이어프램 주변유동이 와류 및 순환영역에 의해 국부적으로 활발해지기 때문 이다. Fig. 5 를 활용하면 연소실 전반에 걸쳐 에 너지 캐스케이드에 의해 매우 작은 크기로 나타 나는 난류구조를 확인할 수 있다. 특히, 다이어프 램을 설치한 유동장의 $\mathrm{POD}$ 결과 중 모드 6-9의 분포는 Fig. 5 를 통해 해석할 수 있다. 그런데 이 난류구조들은 Fig. 2에서 기본형상의 벽면 근처 에서 발생되는 난류구조와 에너지 크기가 유사하 다. 따라서 다이어프램 설치 유무에 따른 에너지 크기 차이가 적으므로, Fig. 4에서 모드 6-9에 이 르는 에너지 비중 또한 비슷하다.

\subsection{4 분출유동이 없는 다이어프램 유동장의 $\mathrm{POD}$ 분석}

고체연료의 기화로 인한 분출유동이 연소실 유동특성에 미치는 영향을 분석하기 위해, 분출 유동을 포함하지 않은 유동장에 대해 추가적인 $\mathrm{POD}$ 분석을 수행하였다. 분출유동이 없는 유동 장의 $\mathrm{POD}$ 결과는 Fig. 6에 정리되어 있다. 또한 분출유동이 있는 경우의 $\mathrm{POD}$ 결과인 Fig. 3과 비교하여, 각 모드별 에너지 특성에 분출유동이 미치는 영향을 분석하였다.

다이어프램과 가까운 영역은 Fig. 6과 Fig. 3 모두 와류 및 순환영역에 의한 난류구조가 관측 되며, 난류구조의 크기도 비슷하다. 따라서 분출 유동으로 인한 유동특성의 변화가 미미하다. 이 러한 현상은 고체연료 표면의 분출유동 유무에

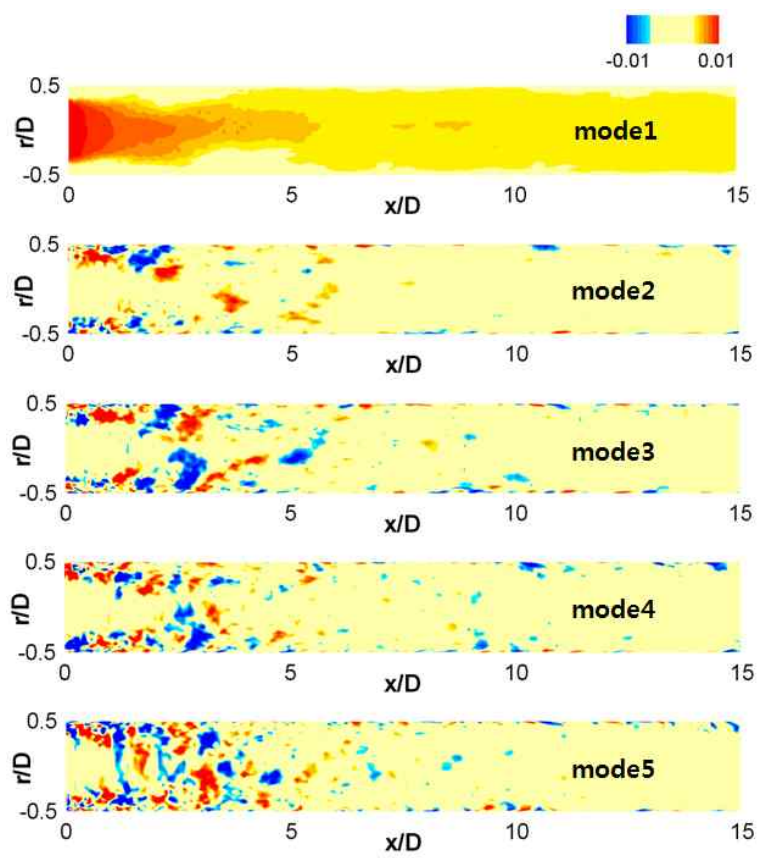

Fig. 6. POD results with diaphragm (no blowing) 


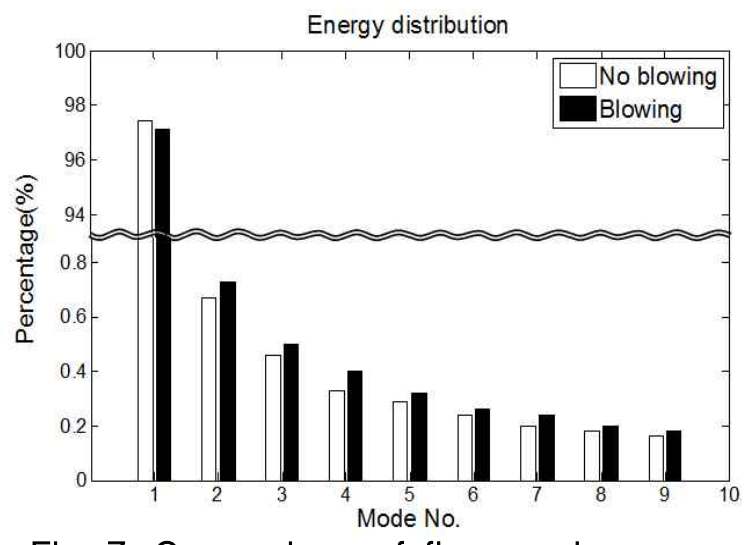

Fig. 7. Comparison of flow mode energy between the cases; blowing vs. no blowing

따른 모드별 에너지 분포를 보여주는 Fig. 7에 도 나타난다. Fig. 7에서 모드 2-5는 다이어프램 근처에서 국부적으로 발생하는 와류 및 순환영역 에 의한 에너지를 나타낸다. 그리고 모드 2-5의 에너지 비중은 분출유동 여부에 관계없이 비슷하 다. 따라서 분출유동이 다이어프램과 가까운 영 역에 미치는 영향은 거의 없다.

한편, 분출유동으로 인한 연소실 후류 벽면근 처의 유동특성 변화를 Fig. 6과 Fig. 3을 비교하 여 확인한 결과, 연소실 후류의 벽면 근처에서 발생되는 작은 크기의 난류구조는 벽면분출이 있 는 경우에 더 많이 발생하는 것으로 보인다. 그 러나 분출유동 여부에 따른 모드별 에너지 분포 를 비교한 Fig. 7을 살펴보면, 연소실 후류 벽면 의 유동모드인 모드 6-9 에너지 분포가 다이어프 램 직후에 발생하는 유동특성이 반영된 모드 2-5 의 에너지 분포에 비해 작음을 알 수 있다.

또한, 분출유동 유무에 따른 모드 6-9의 에너 지 크기도 매우 비슷하게 나타난다. 전체 연소실 관점에서, $\mathrm{POD}$ 결과의 차이가 있어도 그 모드의 에너지 크기가 매우 작으면 유동특성에 미치는 영향은 미미하다. 그러므로 Fig. 6과 Fig. 3에서 나타나는 연소실 후류 벽면의 난류구조 차이를 살펴볼 때 유동특성에 미치는 영향은 거의 없으 며 연소실 하류에서의 연소율도 분출유동 유무에 관계없이 비슷할 것으로 예측된다.

\section{III. 결 론}

하이브리드 로켓 연소실 내부 유동특성을 해 석하기 위해 LES 수치계산 결과에 대한 POD 후 처리 기법을 적용하였다. 특히, 다이어프램의 설 치 및 벽면으로부터 분출되는 유동특성 변화를
분석하기 위해 기본형상, 다이어프램이 설치된 경우, 다이어프램이 설치되고 분출유동이 없는 경우를 각각 비교분석하였다.

기본형상에 대한 $\mathrm{POD}$ 분석 결과, 주 유동을 의미하는 모드 1 과는 별개로 벽면에서 작은 크기 의 난류구조가 발생되는 나머지 모드(모드 2-9)의 특성을 확인하였다. 한편, 다이어프램을 설치한 형상의 $\mathrm{POD}$ 결과는 기본형상의 $\mathrm{POD}$ 결과와 대 체적으로 유사하나, 모드 2-5에서 다이어프램 주 변에 와류 및 순환영역으로 인한 난류구조가 발 생되는 차이를 보였다. 이를 통해 다이어프램 근 처에 한해 국부적으로 강한 유동특성이 나타나는 것을 확인하였다. 따라서 연료의 연소율이 다이 어프램 근처에만 국부적으로 증가하여 불균일한 분포를 나타내는 요인은 다이어프램 근처에서 형 성되는 모드 2-5까지의 유동에너지 상승 때문인 것으로 분석된다.

한편, 고체연료의 기화로 인한 벽면 분출유동 의 모사 여부에 따른 $\mathrm{POD}$ 결과를 비교, 분석하 였다. 그 결과, 다이어프램 주위 영역의 유동특성 을 보여주는 모드 2-5의 에너지 분포는 표면 분 출유동의 유무에 의한 차이가 없음을 확인하였 다. 또한 후류 벽면에서 나타나는 유동 모드 6-9 를 살펴보면, 난류구조의 양적으로 차이를 보이 지만 모드의 총 에너지의 크기는 다이어프램 근 처의 모드(2-5 모드)에 비해 매우 낮다는 것을 알 수 있었다. 따라서 분출유동의 모사 여부가 다이 어프램 근처와 연소실 후류 벽면근처의 유동특성 에 미치는 영향이 거의 없음을 확인하였다.

\section{후 기}

본 연구는 한국연구재단의 우주기술개발사업 (NSL사업, 2013M1A3A3A02041818)의 지원을 받 아 수행한 연구결과임을 밝히며 지원해주신 한국 연구재단에 감사드립니다.

\section{References}

1) Mon, K. O. and Lee, C., "Numerical Investigation on the Vortices Generation on the Blowing Wall with Diaphragm", Asia-Pacific International Symposium on Aerospace Technology, Takamatsu, Japan, 2013.

2) Berkooz, G., Holmes, P., and Lumley, J. L., "The Proper Orthogonal Decomposition in the Analysis of Turbulent Flows", Annual Review of Fluid Mechanics, Vol. 25, 1993, pp. 
539-575.

3) Baltzer, J. R. and Adrian, R. J., "Structure, Scaling, and Synthesis of Proper Orthogonal Decomposition Modes of Inhomogeneous Turbulence", Physics of Fluids, Vol. 23, No. 1, 2011, pp. 015107.

4) Aradag, S., Siegel, S., Seidel, J., Cohen, K., and McLaughlin, T., "Filtered POD-based Low-dimensional Modeling of the 3D Turbulent Flow Behind a Circular Cylinder", International Journal for Numerical Methods in Fluids, Vol. 66, No. 1, 2010, pp. 1-16.

5) Wierman, M., Pomeroy, B., Feldman, T., Hallum, W. Z., and Anderson, W., "Application of Proper Orthogonal Decomposition to Light Intensity Measurements of Combustion Instability", 48th Joint Propulsion Conference \& Exhibit, AIAA 2012-4203, Atlanta, GA, 2012.

6) Kostka, S., Lynch, A. C., Huelskamp, B. C., Kiel, B. V., Gord, J. R., and Roy, S., "Characterization of Flame-shedding Behavior Behind a Bluff-body Using Proepr Orthogonal Decomposition", Combustion and Flame, Vol.159, No. 9, 2012, pp. 2872-2882.

7) Hwang, Y. C. and Lee, C., "The Increase in Regression Rate due to Helical Grain in Solid Fuel of Hybrid Rocket", Journal of The Korean Society Aeronautical and Space Sciences, Vol. 34, No. 12, 2006, pp. 59-66.

8) Carmicino, C. and Sorge, A. R., "Role of Injection in Hybrid Rockets Regression Rate Behavior", Journal of Propulsion and Power, Vol.
21, No. 4, 2005, pp. 606-612.

9) George, P., Krishnan, S., Varkey, P. M., Ravindran, M., and Ramachandran, L., "Fuel Regression Rate in Hydroxyl-terminatedpolybutadiene/gaseous-oxygen Hybrid Rocket Motors", Journal of Propulsion and Power, Vol. 17, No. 1, pp. 35-42.

10) Kerschen, G., Golinval, J. C., Vakaki, A. F., and Bergman, L. A., "The Method of Proper Orthogonal Decomposition for Dynamical Characterization and Order Reduction of Mechanical Systems: An Overview", Nonlinear Dynamics, Vol. 41, No. 1, 2005, pp. 147-169.

11) Sirovich, L., "Turbulence and the Dynamics of Coherent Structures. Part 1: Coherent Structures," Quarterly of Applied Mathematics, Vol. 45, No. 3, 1987, pp. 561-571.

12) Meyer, K. E., Pedersen, J. M., and Ozcan, O., "Turbulent Jet in Crossflow Analysed with Proper Orthogonal Decomposition", Journal of Fluid Mechanics, No. 583, 2007, pp. 199-227.

13) Koo, H., Mon, K. O., and Lee, C., "Effect of a block on flow oscillations near evaporating solid fuel surface", Aerospace Science and Technology, Vol. 30, No. 1, 2013, pp. 269-277.

14) Orellano, A., Wengle, H., "POD Analysis of Coherent Structures in Forced Turbulent Flow over a Fence", Journal of Turbulence, Vol. 2, No. 1, 2001, pp. 008. 